\title{
Gallbladder infarction and liver abscess formation following right hepatic artery chemoembolization for metastatic neuroendocrine tumor
}

\author{
Christopher Sampson • Ryan Petersen
}

Received: 25 August 2009 / Accepted: 1 February 2010/Published online: 9 April 2010

(C) Springer-Verlag London Ltd 2010

\begin{abstract}
A 42-year-old Iraqi woman with hypertension, peptic ulcer disease, and metastatic carcinoid disease presented to the emergency department (ED) with right upper quadrant pain and subjective fevers following chemoembolization for a neuroendocrine tumor of the liver diagnosed by biopsy in Iraq in 2000. The patient had undergone chemoembolization with polyvinyl alcohol particles 3 weeks prior to arrival. Two days following the embolization, because of concern for acute cholecystitis, the patient underwent a right upper quadrant ultrasound. The ultrasound demonstrated a small amount of sludge with no significant gallbladder wall thickening. No detectable blood flow was identified in the anterior gallbladder wall, which was concerning for gallbladder wall ischemia. Following improvement in pain and tolerating a regular diet without difficulty, she was discharged home. She returned to the ED exactly 3 weeks following her procedure. Her exam demonstrated diffuse abdominal tenderness, greatest to palpation in the right upper quadrant. Her laboratory values were unremarkable except an elevated alkaline phosphatase of 231. She underwent a repeat right upper quadrant ultrasound, which demonstrated a partially collapsed gallbladder with a fenestration in the fundus and associated fluid collection, consistent with gallbladder perforation (Fig. 1). She was taken to the interventional radiology suite and underwent the placement of a percutaneous cholecystostomy tube. Three months later, due to persistent pain in the right upper quadrant despite repeated catheter changes, a cholecystectomy was performed. Pathology showed acute and chronic cholecystitis with necrosis. The patient now reports much improvement in her symptoms.
\end{abstract}

C. Sampson $(\bowtie) \cdot$ R. Petersen

Washington University in St. Louis,

St. Louis, MO, USA

e-mail: sampsonc@wusm.wustl.edu

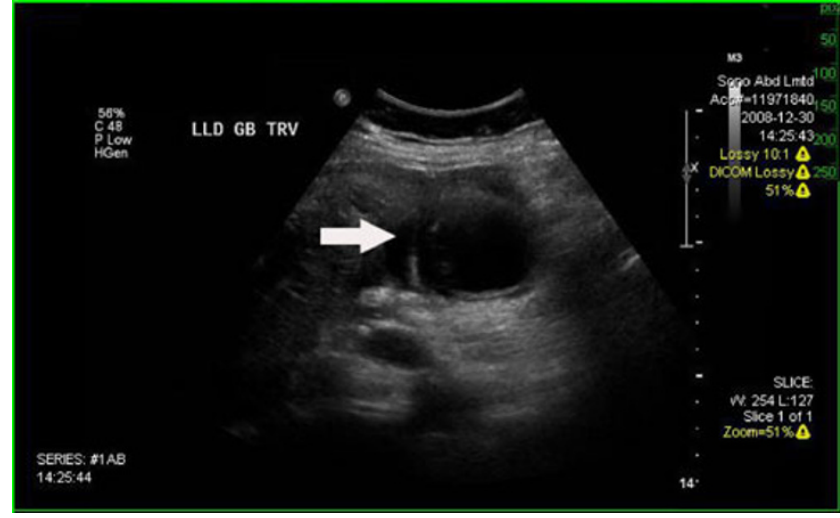

Fig. 1 Long view of gallbladder showing fenestration and pericholecystic fluid

Emergency physicians should have an understanding of the possible complications of chemoembolization. The most common complication is postembolization syndrome, which occurs in up to $90 \%$ of patients. Nausea, vomiting, abdominal pain and fever are characteristic. Fever should typically be low grade and last 1 week [1]. Gallbladder infarction is rare and reported at $1.1 \%$ [2]. Though guided by the patient's history, an emergency physician should have a low threshold for ancillary radiographic imaging to rule out possible complications, some of which may be fatal if missed.

Conflicts of interest None.

\section{References}

1. Leung DA, Goin JE, Sickles C, Raskay BJ, Soulen MC (2001) Determinants of postembolization syndrome after hepatic chemoembolization. J Vasc Interv Radiol 12:321-326

2. Chung JW, Park JH, Han JK, Choi BI, Han MC, Lee HS, Kim CY (1996) Hepatic tumors: predisposing factors for complications of transcatheter oil chemoembolization. Radiology 198:33-40 